\title{
Repeatability and reproducibility of retinal nerve fibre layer thickness measurements with the iVue-100 optical coherence tomographer
}

\author{
Nishanee Rampersad, Rekha Hansraj
}

Discipline of Optometry School of Health Sciences,College of Health Sciences, University of KwaZulu- Natal, Durban, SouthAfrica.

\section{Emails:}

hansrajr@ukzn.ac.za

rampersadn@ukzn.ac.za

\begin{abstract}
Background: Accurate and repeatable measurements of the retinal nerve fibre layer (RNFL) thickness are important in the diagnosis and management of glaucoma and other disorders.

Objective: To assess the repeatability and reproducibility of the iVue-100 optical coherence tomographer (OCT).

Methods: The thickness of the RNFL was measured for 50 healthy participants using the iVue-100 OCT. Although both eyes per participant were measured, only right eyes were analysed here. Repeatability and reproducibility of the iVue-100 OCT were assessed using the intraclass correlation coefficient (ICC), coefficient of variation (CoV), paired t-tests and Bland-Altman analysis.

Results: Good intra-observer repeatability was obtained as indicated by the ICC of observer 1 (range: 0.941 - 0.976) and observer 2 (range: $0.829-0.953$ ) as well by the CoV of observer 1 (range: $0.098-0.137$ ) and observer $2(0.091-0.132)$. In terms of inter-observer reproducibility, significant differences $(p<0.05)$ in mean measurements between the observers were noted for the average RNFL readings and in the superior and inferior quadrants as assessed with paired t-tests. Even though significant inter-session differences were found for the average RNFL thickness and the superior quadrant $(p=0.003$ and $p=0.013$, respectively), excellent ICCs were obtained for inter-session reproducibility (range: $0.914-0.979$ ).

Conclusion: The iVue-100 OCT demonstrated good repeatability and reproducibility for RNFL thickness measurements.

Keywords: Retinal nerve fibre layer thickness, optical coherence tomography, repeatability, reproducibility, iVue-100 OCT.

DOI: https://dx.doi.org/10.4314/ahs.v18i2.15

Cite as: Rampersad N, Hansraj R. Repeatability and reproducibility of retinal nerve fibre layer thickness measurements with the iV ue-100 optical coherence tomographer. Afri Health Sci. 2018;18(2): 304-312. https:/ / dx.doi.org/10.4314/ abs.v18i2.15
\end{abstract}

\section{Corresponding author: \\ Rekha Hansraj, \\ Discipline of Optometry School \\ of Health Sciences, \\ College of Health Sciences, \\ University of KwaZulu- Natal \\ Durban, SouthAfrica \\ Tel: +27312607089 \\ Fax: +27 312607666 \\ Email: hansrajr@ukzn.ac.za}

\section{Introduction}

The retinal nerve fibre layer (RNFL) lies between the ganglion cell layer and inner limiting membrane of the retina. ${ }^{1}$ As it comprises of the axons of the ganglion cells, it is sometimes referred to as the axon layer. These axons transmit the chemical message from the retina to synapse at the lateral geniculate nucleus before reaching the occipital cortex. There is a varied but definite retinotopic arrangement of the nerve fibres as they (neural impulses) make their way through the visual pathway in preparation for impulses to be received optimally at the occipital cortex. The thickness of the RNFL on the optic

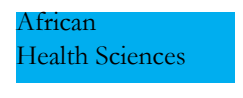

(C) 2018 Rampersad et al. Licensee African Health Sciences. This is an Open Access article distributed under the terms of the Creative commons Attribution License (https://creativecommons.org/licenses/by/4.0), which permits unrestricted use, distribution, and reproduction in any medium, provided the original work is properly cited. 
nerve head is found to vary in the four quadrants (superior, inferior, nasal and temporal) being thickest in the inferior quadrant. ${ }^{1,2}$

The thickness of the RNFL varies with age, ethnicity, axial length and optic disc area apparently but not with gender. $^{3}$ Various ocular pathologies including retinitis pigmentosa and glaucoma result in an altered RNFL thickness ${ }^{4-6}$ making the clinical measurement of RNFL thickness of importance in both the diagnosis and management of ocular conditions.

Glaucoma is the second leading cause of blindness accounting for $10.1 \%$ of global blindness. ${ }^{7,8}$ In Africa, primary open-angle glaucoma is the predominant form of glaucoma and is likely to affect 8.0 million African individuals by the year 2020. ${ }^{9}$ Glaucoma is associated with thinning of the retinal nerve fibre layer (RNFL) and loss of ganglion cells. ${ }^{10,11}$ Consequently, assessment of the RNFL is important in the screening, diagnosis and monitoring of glaucoma since RNFL changes preceed visual field changes. ${ }^{12,13}$ Systemic conditions such as multiple sclerosis have also been associated with RNFL thinning. ${ }^{14}$

Common methods used to assess the RNFL include scanning laser polarimetry, confocal scanning laser ophthalmoscopy, fundus photography and optical coherence tomography. ${ }^{10}$ Optical coherence tomography, a non-invasive method that produces high-resolution, cross-sectional micrometre-scale images of biological structures, is frequently used to assess the RNFL. ${ }^{10,15}$ The principle of OCT is analogous to ultrasound except that reflected light waves and not reflected sound waves are measured and analysed. ${ }^{16}$ Compared to traditional time-domain OCT devices that were introduced in the early 1990s, the newer generation Fourier/spectral-domain OCT devices provide higher axial resolutions, faster scanning speeds and better eye movement tracking. ${ }^{17,18}$

Repeatability describes the ability of an instrument to provide consistent measurements for a single observer under the same conditions on the same visit. In addition, reproducibility of refers to consistent measurements when an instrument is used by two different observers (inter-observer repeatability) and in two separate sessions (inter-session repeatability).

Good repeatability and reproducibility are characteristics of an instrument for it to be useful in research and in clinical practice. ${ }^{19}$ Previous studies ${ }^{19-22}$ on the repeatability of RFNL thickness using OCT included time-domain and Fourier domain OCTs and their comparisons. However, many of these studies were on American and European samples with little to no inclusion of Asian and African individuals. ${ }^{3}$ Furthermore, to the researchers' best knowledge, limited studies have investigated the repeatability of RNFL measurements using the iVue-100 OCT. Therefore, this study investigated repeatability of the iVue-100 OCT for RNFL thickness measurements in a South African sample.

\section{Methods}

Convenience sampling was used to recruit 50 participants, of all races, gender and ages in this observational cross-sectional study. The study followed the tenets of the Declaration of Helsinki and all participants were required to give written informed consent. Ethical approval was obtained from the Biomedical Research and Ethics committee (BE024/13) of the UKZN. All participants had normal corneal topography, visual acuity of at least $20 / 20$ (aided or unaided) and no history of ocular injury and/or surgery.

The RNFL thickness was scanned and measured using the Optovue iVue-100 OCT device on both eyes per participant most frequently before midday, and over a period of 10 weeks. This Fourier-domain OCT device operates at a scanning speed of 26000 A-scans per second with a frame rate of 256 to $4096 \mathrm{~A}$-scans per frame. ${ }^{23}$ The axial and transverse resolutions of the iVue-100 OCT device are $5 \mu \mathrm{m}$ and $15 \mu \mathrm{m}$ respectively (manual). A pre-programmed algorithm in the iVue-100 OCT device automatically determines the RNFL thickness as the distance in micrometres between the anterior and posterior boundaries of the highly reflective retinal layer. ${ }^{10,23}$ The optic nerve head scan protocol which consists of 12 radial $(3.4 \mathrm{~mm})$ line scans of 459 A-scans each was used to measure the RNFL thickness. In this scan protocol, the RNFL thickness is measured along a $3.45 \mathrm{~mm}$ diameter circular ring centred on the optic disc. ${ }^{23}$ The optic nerve head scan automatically determines the average RNFL thickness in the superior $\left(46^{\circ}\right.$ to $\left.135^{\circ}\right)$, nasal $\left(136^{\circ}\right.$ to $225^{\circ}$ ), inferior $\left(226^{0}\right.$ to $\left.315^{\circ}\right)$ and temporal $\left(316^{\circ}\right.$ to $\left.45^{\circ}\right)$ quadrants as well as the global RNFL thickness displayed as the "average RNFL thickness" on the scan (Figure 1). 


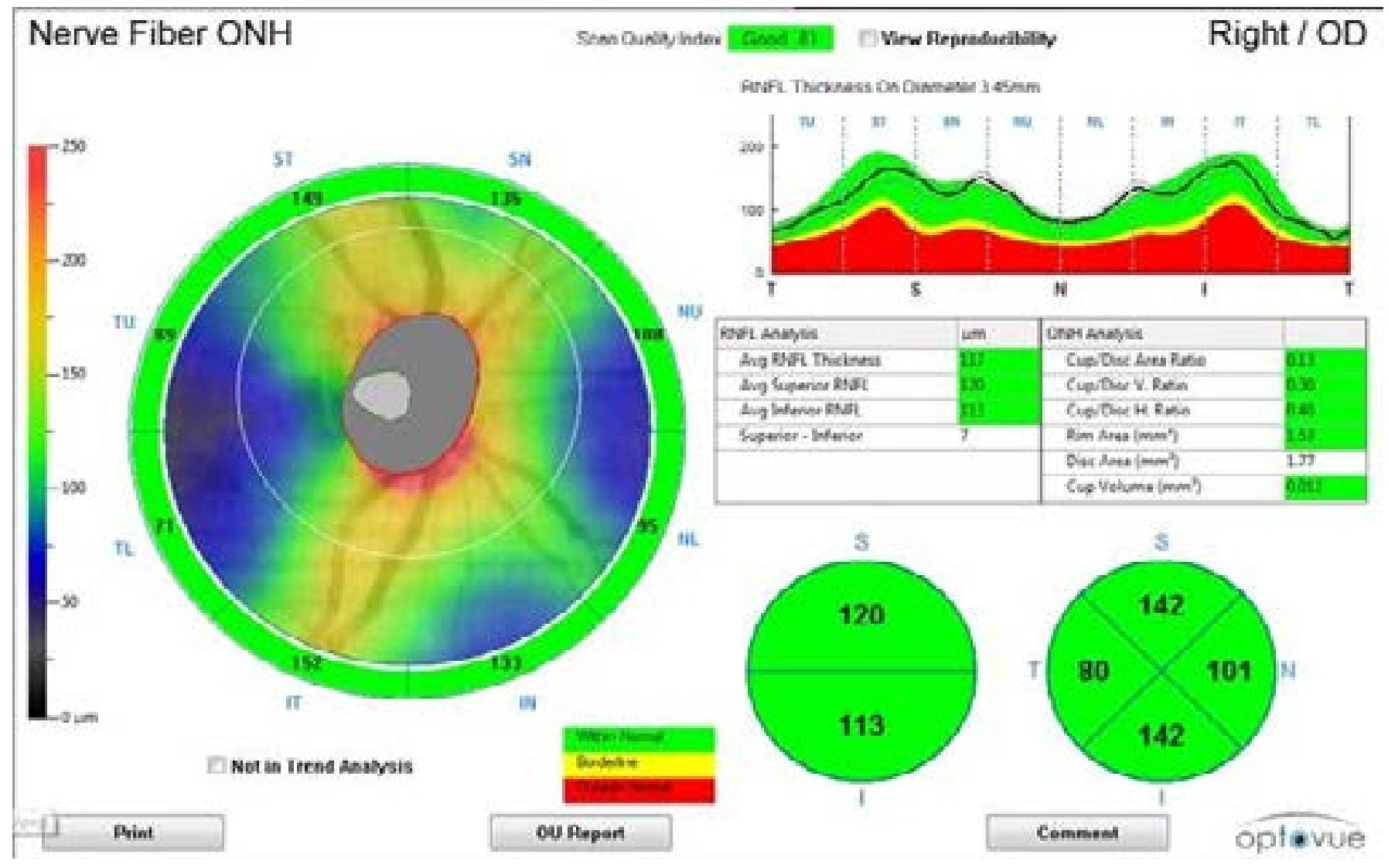

Figure 1: RNFL thickness display of the optic nerve head scan

A laptop screen was used to monitor the real-time image of the participant's eye and RNFL when scanning while the participant fixated an internal fixation target. The participant's head was stabilized using forehead and chin rests. Repeat scans were taken if the scan quality index was less than 27 and/or labelled as 'poor' on the laptop screen display. ${ }^{23}$ For the assessment of intra-observer repeatability, the optic nerve head scanning protocol was repeated three times on the same participant. Inter-observer repeatability was assessed by having a second observer repeat the optic nerve head scanning protocol on the same participant at each visit. For inter-session repeatability, observer one repeated the scanning protocol on the same participant on another day. Each observer re-aligned the iVue-100 OCT device before capturing each scan.

Data were analysed using the Statistical Package for Social Sciences (SPSS) version ${ }^{24}$. Repeatability of the measurements was reported in terms of the intraclass correlation coefficient (ICC) and coefficient of variation (CoV).
Bland-Altman analysis and t-tests were also used to report on the inter-observer and inter-session repeatability. The significance level was set at $95 \%$ with p-value of $\leq 0.05$.

\section{Results}

\section{Demographics}

The sample consisted of 50 participants with almost twice as many females $(n=32)$ than males $(n=18)$. The ages of the participants ranged between 18 and 51 years with a mean of $23.88 \pm 6.93$ years (median age $=22.00$ years). The majority of the participants were Indian (54\%) followed by Black (36\%), White (8\%) and Asian (2\%). Half of the participants has spherical equivalent refractive errors less than or equal to $0.50 \mathrm{D}$. The spherical equivalent of the right eye ranged from -8.38 to $+1.63 \mathrm{D}$ and that of the left eye ranged from -9.63 to $+3.00 \mathrm{D}$. Due to the limited sample size the correlation between refractive error and nerve fibre layer was not considered in this study. The right and left eye measurements correlated in the four quadrants $(0.940 \geq \mathrm{r} \geq 0.750)$ with differences $\leq 4.60$, therefore only the right eye measurements were analysed. 

rants.

Table 1: Intraclass correlation coefficient with $95 \%$ confidence intervals and CoV for each observer, for RNFL thickness measured for the different quadrants of the right eye

\begin{tabular}{lllll}
\hline & $\begin{array}{l}\text { OBSERVER 1 } \\
\text { ICC (95\% CI) }\end{array}$ & CoV & $\begin{array}{l}\text { OBSERVER 2 } \\
\text { ICC (95\% CI) }\end{array}$ & CoV \\
\hline Average & $0.976(0.962-0.986)$ & 0.098 & $0.953(0.925-0.972)$ & 0.091 \\
Superior & $0.968(0.948-0.981)$ & 0.137 & $0.919(0.870-0.952)$ & 0.125 \\
Inferior & $0.972(0.956-0.983)$ & 0.111 & $0.872(0.795-0.923)$ & 0.108 \\
Nasal & $0.941(0.906-0.965)$ & 0.134 & $0.829(0.727-0.898)$ & 0.140 \\
Temporal & $0.958(0.932-0.975)$ & 0.132 & $0.918(0.868-0.951)$ & 0.132 \\
\hline
\end{tabular}

Excellent intra-observer repeatability was noted as the ICCs for observer one ranged from 0.941 to 0.976 and that for observer two from 0.829 to 0.953 . The highest ICCs were noted for the average RNFL thickness and the lowest $(0.941$ and 0.829$)$ were noted in the nasal quadrant for the two observers. The $\mathrm{CoV}$ for observer one ranged from 0.098 to 0.137 and that of observer two, from 0.091 to 0.132 indicating good intra-observer repeatability.

\section{Inter-observer repeatability}

For the different quadrants of the right eyes. Table 2 also shows the Bland and Altman limits of agreement (LoA). The Paired t-tests were used to determine the t-values and $\mathrm{p}$-values as an indication of significant differences between observers.

There were no statistically significant differences in means between the two observers for the nasal and temporal quadrants $(\mathrm{p}>0.05)$. While statistically significant differences in means were found for the superior, inferior and average RNFL $(p<0.05)$, the mean differences were less than $3 \mu \mathrm{m}$ (Table 2). The ICCs ranged between 0.906 and 0.976 indicating excellent repeatability.

Table 2: The mean differences, and their standard deviations, of RNFL thickness $(\mu \mathrm{m})$ between two observers, Bland and Altman upper and lower LoA, $t$-values and $p$-values from the Paired $t$-tests and the ICC

\begin{tabular}{|c|c|c|c|c|c|c|c|}
\hline & $\begin{array}{l}\text { Mean diff } \\
(\mu \mathrm{m})\end{array}$ & $\mathrm{SD}(\mu \mathrm{m})$ & $\begin{array}{l}\text { Upper } \\
\text { LoA } \\
\end{array}$ & $\begin{array}{l}\text { Lower } \\
\text { LoA }\end{array}$ & $\begin{array}{l}t- \\
\text { value }\end{array}$ & $p$-value & ICC \\
\hline Average & 1.047 & 2.959 & 6.847 & -4.753 & 2.501 & 0.016 & 0.976 \\
\hline Superior & 2.667 & 6.998 & 16.383 & -11.049 & 2.640 & 0.011 & 0.954 \\
\hline Inferior & 2.507 & 8.121 & 18.424 & -13.410 & 2.183 & 0.034 & 0.912 \\
\hline Nasal & -0.253 & 6.631 & 12.744 & -13.250 & -0.270 & 0.788 & 0.906 \\
\hline Temporal & -0.403 & 4.993 & 9.383 & -10.189 & -0.559 & 0.579 & 0.932 \\
\hline
\end{tabular}

Bland-Altman plots were used to graphically compare the average RNFL thickness measurements of the two observers (Figure 2). All measurements were within the 95\% LoA with the exception of three. The mean difference was small at $1.047 \mu \mathrm{m}$. 


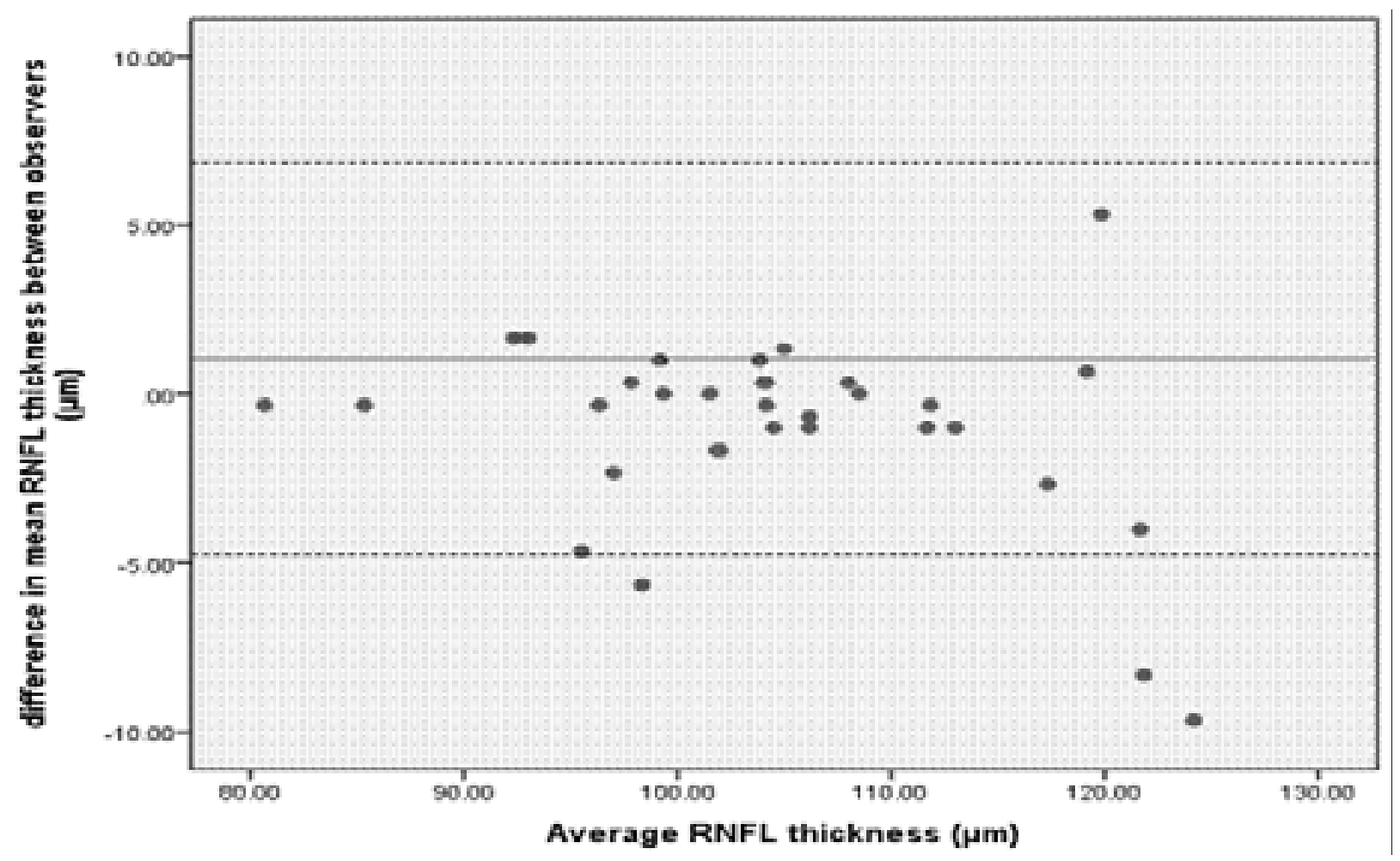

Figure 2: Bland-Altman plot comparing RNFL thickness measurements of the right eyes taken by observer one and observer two. The solid line represents the mean difference and the dashed lines represent the upper and lower LoA. Three points were outside the $95 \%$ LoA region.

\section{Inter-session repeatability}

The measurements of observer one were used to determine the inter-session repeatability as this observer had completed more inter-session repeat readings which were taken on two separate sessions. The interval between sessions 1 and 2 ranged between 1 and 70 days. The mean difference of the RNFL readings ranged from $0.222 \mu \mathrm{m}$ to $4.061 \mu \mathrm{m}$ (Table 3) with the ICC ranging between 0.914 and 0.979. Paired t-tests were used to determine the $\mathrm{t}$-values and $\mathrm{p}$-values as an indication of significant differences between sessions. Statistically significant differences in the mean RNFL thickness measurements between sessions were noted in the average and superior quadrant.

Table 3: The mean differences and their standard deviations, of RNFL thickness $(\mu \mathrm{m})$ for observer one taken over two sessions, Bland and Altman upper and lower LoA, and $t$ values and $p$-values from Paired $t$-tests and ICC

\begin{tabular}{llllllll}
\hline & $\begin{array}{l}\text { Mean diff } \\
(\boldsymbol{\mu m})\end{array}$ & $\mathbf{S D}(\boldsymbol{\mu m})$ & $\begin{array}{l}\text { Upper } \\
\text { LoA }\end{array}$ & $\begin{array}{l}\text { Lower } \\
\text { LoA }\end{array}$ & $\begin{array}{l}\boldsymbol{t} \text { - } \\
\text { value }\end{array}$ & $\begin{array}{l}\boldsymbol{p} \text { - } \\
\text { value }\end{array}$ & ICC \\
\hline Average & 1.465 & 2.625 & 6.610 & -3.680 & 3.206 & 0.003 & 0.979 \\
Superior & 4.061 & 8.841 & 21.389 & -13.267 & 2.639 & 0.013 & 0.914 \\
Inferior & 1.455 & 5.321 & 11.884 & -8.974 & 1.570 & 0.126 & 0.969 \\
Nasal & 0.222 & 4.421 & 8.887 & -8.443 & .289 & 0.775 & 0.942 \\
Temporal & 0.162 & 3.654 & 7.324 & -7.000 & .254 & 0.801 & 0.965 \\
\hline
\end{tabular}


Bland- Altman plots were used to graphically compare the average RNFL thickness measurements taken by observer one over two sessions (Figure 3). All measure- ments were within the $95 \%$ LoA with the exception of only one measurement. The mean difference was less than $1.465 \mu \mathrm{m}$.

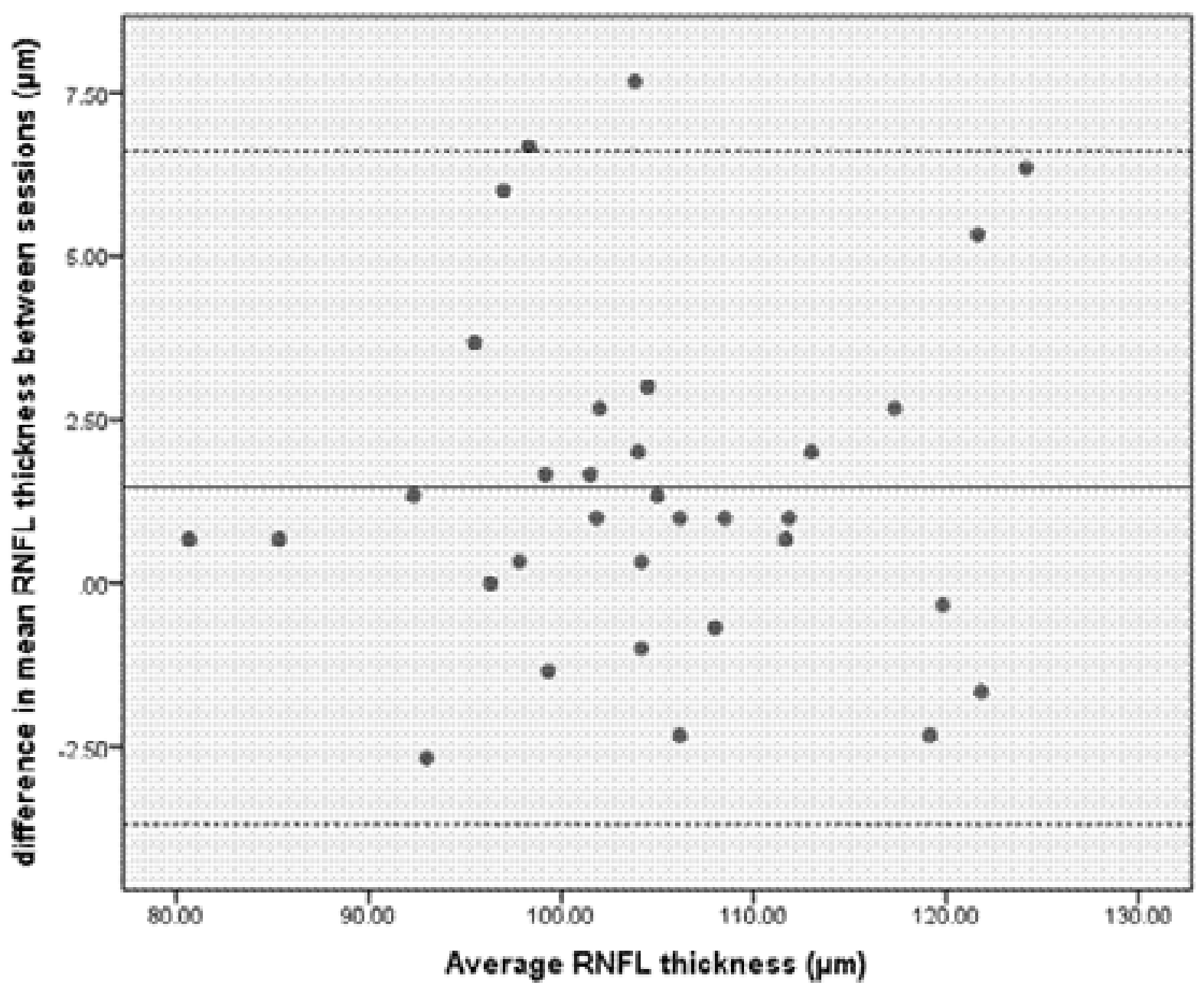

Figure 3: Bland-Altman plot comparing average RNFL measurements of the right eyes taken by observer one in two separate sessions. The solid line represents the mean difference and the dashed lines represent the upper and lower LoA.

\section{Discussion}

The estimation of an instrument's repeatability and reproducibility is of paramount importance ${ }^{19}$ particularly one that is being used for clinical and research applications. Accurate and reliable measurements of the RNFL thickness is necessary in both the diagnosis and management of retinal disorders particularly glaucoma and retinitis pigmentosa. ${ }^{4-6}$ Optical coherence tomography provides an accurate, non-invasive and rapid quantitative assessment of RNFL thickness. ${ }^{24}$ The iVue-100, a spectral domain OCT, has gained popularity in its usage in the clinical field, however it's repeatability and reproducibility for measurement of RNFL thickness has not been extensively studied previously.

Repeatability of the iVue-100 OCT was assessed using the ICC and CoV as the indicators. The ICC can lie anywhere between 0 and 1 , with a higher ICC indicating min- 
imal fluctuation in repeated readings., ${ }^{5,19}$ Furthermore, an ICC of between 0.81 and 0.99 represents good agreement between repeated measurements. ${ }^{25}$ The ICCs of both observers in this study were greater than 0.8 thereby implying good intra-observer repeatability.

The $\mathrm{CoV}$ indicates the measurement variability in relation to the mean and has been used in other repeatability studies. ${ }^{5,19}$ A CoV $<0.1$ indicates high repeatability. ${ }^{20}$ The CoVs for both observers ranged from 0.091 to 0.137 again indicating good intra-observer repeatability. In the present study, the best intra-observer repeatability was noted for the average RNFL thickness measurements for both observer 1 and 2 in terms of the ICC and CoV which is consistent with the findings of other studies. ${ }^{19-22}$ The poorest intra-observer ICC was noted for the superior quadrant for observer 1 and the nasal quadrant for observer 2. Similar discrepancies have been reported for intra-observer repeatability as González-García et $\mathrm{al}^{19}$ and Garcia-Martin et $\mathrm{al}^{21}$ found the lowest intra-observer ICC for RNFL thickness measurements in the nasal quadrant while Paunescu et $\mathrm{al}^{22}$ found the inferior quadrant to have the lowest ICC. It should be noted that the current study calculated the ICC and CoV based on the mean difference between the measurements, however previous studies have used the actual mean RNFL thickness.

Clinically when monitoring the progression of a disorder it is essential that the smallest changes are detected which depend on the instrument reproducibility. ${ }^{5,19}$ The Paired t-tests and Bland-Altman analysis were used in addition to the ICC to assess the reproducibility, which has been the case in previous studies. ${ }^{20,22,25}$

The ICC indicated excellent inter-observer and inter-session repeatability (all ICCs $\geq 0.906$ ). However, the Paired t-tests noted significant inter-observer mean differences for the average RNFL thickness $(1.047 \mu \mathrm{m})$, superior $(2.667 \mu \mathrm{m})$ and inferior $(2.507 \mu \mathrm{m})$ quadrants. Assuming the normal average RNFL thickness as being approximately $104.27 \mu \mathrm{m}$ and that an $8.4 \%(8.75 \mu \mathrm{m})$ RNFL loss is required before visual field changes are detected ${ }^{26}$ these mean differences of less than $3 \mu \mathrm{m}$ as found in the present study are possibly not clinically significant. Similar mean differences for inter-observer repeatability were reported by Gürses-Özden et $\mathrm{al}^{18}$ of $2.9 \mu \mathrm{m}$ for the supe- rior quadrant and $3.3 \mu \mathrm{m}$ for the inferior quadrant using the fast scan protocol on the Carl Zeiss Meditec OCT-3, however, their Paired t-tests did not show these differences to be significant. Also, the sample size for the study by Gürses-Özden et $\mathrm{al}^{20}$ was only 10 subjects and the pupils were dilated unlike in the present study.

In our study, significant inter-session differences as indicated by Paired t-tests were only noted for the average RNFL thickness $(1.465 \mu \mathrm{m}, \mathrm{p}=0.003)$ and in at superior quadrant $(4.061 \mu \mathrm{m}, \mathrm{p}=0.013)$. Even though Gürses-Özden et $\mathrm{al}^{19}$ found statistically insignificant inter-session RNFL thickness measurements, the mean inter-session differences were higher (range: $1.067 \mu \mathrm{m}$ to $6.800 \mu \mathrm{m}$ ) than that found in our study. Garcia-Martin et $\mathrm{al}^{21}$ reported much smaller inter-session mean differences (range: $0.2 \mu \mathrm{m}$ to $1.27 \mu \mathrm{m}$ ) using a Fourier-domain OCT as in the present study unlike Gürses-Özden et $\mathrm{al}^{20}$ who used a time-domain device.

Bland-Altman analysis was further used to quantify the agreement between inter-observer and inter-session measurements for the average RNFL thickness. Generally agreement between two measurements is concluded if $95 \%$ of the data points lie within two standard deviations of the mean difference (LoA), when using this analysis. ${ }^{27,28}$ The LoA describe the variability of repeated measurements either between two observers and/or two different sessions. In the current study, good repeatability was obtained for inter-session repeatability as $97 \%$ of the data points were within the upper and lower LoA, but this was not the case for inter-observer repeatability as only 91\% of the data points were within the LoA for the average RNFL thickness. The size of the LoA for inter-observer and inter-session repeatability were 11.60 and $10.29 \mu \mathrm{m}$, respectively. However, the Bland-Altman LoA should be interpreted not only statistically but also for their clinical significance. $^{29,30}$ The mean differences for both inter-observer and inter-session repeatability were less than $2 \mu \mathrm{m}$ and again may be clinically insignificant.

Previous OCT studies ${ }^{20,31-33}$ have noted the average RNFL thickness measurements to be the most reproducible and the least reproducible to be the nasal region which they related to low reflectance of light reaching the aperture in the nasal region and the greater number of blood vessels 
in the nasal peripapillary region compared to other peripapillary regions. In the current study, the average RNFL thickness was most reproducible in all instances, however while the nasal quadrant was the least reproducible for intra- and inter-observer repeatability, it was the superior quadrant that showed the least inter-session reproducibility. In spite of this, for the least reproducible quadrants the ICC were all greater than 0.905 and the mean differences less than $4.5 \mu \mathrm{m}$. The results of our study therefore suggest that while the iVue-100 OCT has good repeatability and reproducibility, variations in consistency of RNFL thickness measurements in all quadrants may occur.

Good repeatability and reproducibility of the iVue-100 OCT were demonstrated in 50 normal eyes, however future studies should focus on the repeatability of this instrument in larger samples and also in eyes particularly with glaucoma and possibly other conditions such as retinitis pigmentosa. Comparisons with other spectral-domain OCTs that may have different scanning speeds, axial resolution, signal strengths and algorithms would also be useful.

\section{Financial support and sponsorship}

Nil.

\section{Conflicts of interest}

There are no conflicts of interest.

\section{References}

1. Wang YX, Pan Z, Zhao L, You QS, Xu L, Jonas JB. Retinal Nerve Fiber Layer Thickness. The Beijing Eye Study 2011. PLoS One. 2013; 8 (6): e66763.

2. Sony P, Sihota R, Tewari HK, Venkatesh P, Singh R. Quantification of the retinal nerve fibre layer thickness in normal Indian eyes with optical coherence tomography. Indian J Ophthalmol. 2004; 52 (4): 303-309.

3. Budenz DL, Anderson DR, Varma R, Schuman J, Cantor L, Savell J et al. Determinants of normal retinal nerve fiber layer thickness measured by Stratus OCT. Ophthalmology. 2007; 114 (3): 1046-1052.

4. Walia S, Fishman GA, Edward DP, Lindeman M. Retinal nerve fiber layer defects in RP patients. Invest Ophthalmol Vis Sci. 2007; 48 (10): 4748-4752.

5. Ara M, Ferreras A, Pajarin AB, Calvo P, Figus M, Frezzotti P. Repeatability and Reproducibility of Retinal
Nerve Fiber Layer Parameters Measured by Scanning Laser Polarimetry with Enhanced Corneal Compensation in Normal and Glaucomatous Eyes. Bio Med Research International. 2015; Article ID 729392, 6 pages.http://dx.doi. org/10.1155/2015/729392.

6. Gardiner SK, Fortune B, Demirel S. Localized Changes in Retinal Nerve Fiber Layer Thickness as a Predictor of Localized Functional Change in Glaucoma. Am J Ophthalmol. 2016; 170: 75-82.

7. Pascolini D, Mariotti SP. Global estimates of visual impairment: 2010. Br J Ophthalmol. 2012; 96 (5): 614-618.

8. Resnikoff S, Pascolini D, Mariotti SP, Pokharel GP. Global magnitude of visual impairment caused by uncorrected refractive errors in 2004. Bull World Health Organ. 2008; 86 (1): 63-70.

9. Quigley HA, Broman AT. The number of people with glaucoma worldwide in 2010 and 2020. Br J Ophthalmol. 2006; 90 (3): 262-267.

10. Townsend KA, Wollstein G, Schuman JS. Imaging of the retinal nerve fiber layer for glaucoma. Br J Ophthalmol. 2009; 93 (2): 139-143.

11. Almasieh M, Wilson AM, Morquette B, Cueva Vargas JL, Di Polo A. The molecular basis of retinal ganglion cell death in glaucoma. Prog Retin Eye Res. 2012; 31 (2): 152-181.

12. Sommer A, Katz J, Quigley HA, et al. Clinically detectable nerve fiber atrophy precedes the onset of glaucomatous field loss. Arch Opbthalmol. 1991; 109 (1): 77-83.

13. Harwerth RS, Carter-Dawson L, Shen F, Smith EL 3rd, Crawford ML. Ganglion cell losses underlying visual field defects from experimental glaucoma. Invest Ophthalmol Vis Sci. 1999; 40 (10): 2242-2250.

14. Abalo-Lojo JM, Limeres CC, Gómez MA, Baleato-González S, Cadarso-Suárez C, Capeáns-Tomé C, Gonzalez F. Retinal nerve fibre layer thickness, brain atropy, and disability in multiple sclerosis patients. J Neurophthalmol. 2014; 34 (1): 23-8.

15. Hrynchak P, Simpson T. Optical coherence tomography: an introduction to the technique and its use. Optom Vision Sci. 2000; 77 (7): 347-56.

16. Huang D, Swanson EA, Lin CP, Schuman JS, Stinson WG, Chang W et al. Optical coherence tomography. Science. 1991; 254 (5035): 1178-1181.

17. Vizzeri G, Weinreb RN, Gonzalez-Garcia AO, Bowd C, Medeiros FA, Sample PAet al. Agreement between spectral-domain and time-domain OCT for measuring RNFL thickness. Br J Ophthalmol. 2009; 93 (6): 775-781. 
18. Wylęgała E, Teper S, Nowińska AK, Milka M, Dobrowolski D. Anterior segment imaging: Fourier domain optical coherence tomography versus time-domain optical coherence tomography. J Cataract Refr Surg. 2009; 35 (8): 1410-1414.

19. González-García AO, Vizzeri G, Bowd C, Medeiros FA, Zangwill LM, Weinreb RN. Reproducibility of RTVue Retinal Nerve Fiber Layer Thickness and Optic Disc Measurements and Agreement with Stratus Optical Coherence Tomography Measurements. Am J Ophthalmol. 2009; 147 (6): 1067-1074.

20. Gürses-Özden R, Teng C, Vessani R, Zafar S, Liebmann JM, Ritch R. Macular and retinal nerve fiber layer thickness measurement reproducibility using optical coherence tomography (OCT-3). J Glaucoma. 2004; 13 (3): 238-244.

21. Garcia-Martin E, Pinilla I, Idoipe M, Fuertes I, Pueyo V. Intra and interoperator reproducibility of retinal nerve fibre and macular thickness measurements using Cirrus Fourier-domain OCT. Acta Ophthalmol. 2011; 89 (1): e23-e29.

22. Paunescu LA, Schuman JS, Price LL, Stark PC, Beaton S, Ishikawa H. Reproducibility of Nerve Fiber Thickness, Macular Thickness, and Optic Nerve Head Measurements Using Stratus OCT. Invest Ophthalmol Vis Sci. 2004; 45 (6): 1716-1724.

23. Optovue (2011). iVue100 user's manual version 1.9. United States of America, Optovue Inc.

24. Kronfeld PC, McHugh G, Polyak SL. The human eye in anatomical transparencies. New York: Bausch and Lomb Optical Company, 1944.
25. Landis JR, Koch GG. The measurement of observer agreement for categorical data. Biometrics. 1977; 33 (1): 159-174.

26. Giani A, Cigada M, Choudhry N, Deiro AP, Oldani M, Pellegrini $\mathrm{M}$ et al. Reproducibility of retinal thickness measurement on normal and pathologic eyes by different optical coherence tomography instruments. Am J Ophthalmol. 2010; 150 (6): 815-824.

27. Alasil T, Wang K, Yu F, Field MG, Lee H, Baniasadi $\mathrm{N}$ et al. Correlation of retinal nerve fibre layer thickness and visual fields in glaucoma: a broken stick model. Am J Ophthalmol. 2014; 157 (5): 953-959.

28. Muscat S, Parks S, Kemp E, Keating D. Repeatability and reproducibility of macular thickness measurements with the Humphrey OCT system. Invest Ophthalmol Vis Sci. 2002; 43 (2): 490-495.

29. Giavarina D. Understanding Bland-Altman analysis. Biochemia Medica. 2015; 25 (2): 141-151.

30. Bland JM, Altman DG. Statistical methods for assessing agreement between two methods of clinical measurement. Int J Nurs Stud. 2010; 47 : 931-936.

31. Bland M. Clinical measurement. An introduction to medical statistics. New York: Oxford University Press, 2015.

32. Baumann M, Gentile RC, Liebmann JM, Ritch R. Reproducibility of retinal thickness measurements in normal eyes using optical coherence tomography. Ophthalmic Surg Lasers. 1998; 29 (4): 280-285.

33. Massin P, Vicaut E, Haouchine B, Erginay A, Paques M, Gaudric A. Reproducibility of retinal mapping usingoptical coherence tomography. Arch Ophthalmol-Chic. 2001; 119 (8): 1135-1142. 